\title{
Experimentally induced variation in hemocyte density for Ruditapes philippinarum and $R$. decussatus (Mollusca, Bivalvia)
}

\author{
R. Oubella, P. Maes, C. Paillard, M. Auffret* \\ URA CNRS D1513, Laboratoire de Biologie Marine, Institut d'Etudes Marines, Université de Bretagne Occidentale, \\ F-29287 Brest Cédex, France
}

\begin{abstract}
Hemocytes represent the most important internal defense mechanism against foreign material in marine bivalve molluscs. Variations in their density were induced in the hemolymph of 2 economically important clam species (Ruditapes philippinarum and $R$. decussatus) after challenge with a pathogenic bacteria (Vibrio P1) and after starvation. The number of circulating hemocytes increased in both species $72 \mathrm{~h}$ post-challenge when compared to control animals. Following 1 wk starvation, a marked reduction of hemocyte density occurred compared to the control values. It is suggested that reversible migration of hemocytes from the tissues to the circulatory compartment or vice versa explains these variations. Consequently, the hemocyte density may be a quantifiable parameter of the immunodefense response of bivalve molluscs to physiological or pathological stress.
\end{abstract}

\section{INTRODUCTION}

The high risk of disease and mass mortalities caused by intensive breeding methods constitute limiting factors in the development of marine mollusc aquaculture (Fisher 1988). Various pathogens and infectious agents are the cause of epizootic diseases. During summer 1987, French populations of the clam Ruditapes philippinarum were heavily affected by the Brown Ring Disease (BRD) (Paillard et al. 1989). This disease was experimentally transmitted to healthy individuals by inoculation of a suspension of this bacterium Vibrio P1 into the pallial cavity (Paillard \& Maes 1990). More recently, the symptoms of this disease were observed in several European aquaculture sites. However, this pathogen is not specific since Maes \& Paillard (1992) have demonstrated that $R$. decussatus and other Veneridae can also present the symptoms of BRD, although those were not related to mass mortalities. The

\footnotetext{
- Addressee for correspondence
}

reasons for the reduced pathogenicity of the BRD agent in those species are not known.

Attempts to understand molluscan diseases have led to the concept that physiological stress may affect their ability to resist pathogens in part by depressing their internal defense system, and therefore represents an aggravating factor in mortality. In bivalve molluscs, internal defense is primarily cellular and relies on the hemocytes, circulating cells of the hemolymph (Cheng 1981, Fisher 1986). The number and variability of circulating cells are believed to be essential parameters that could characterise immune capacity.

Experiments were designed to determine the effect on hemocyte density of 2 factors known to have harmful physiological effects: challenge with a pathogenic bacterium and starvation. Two species of clams were challenged, Ruditapes philippinarum and $R$. decussatus, the former becoming heavily infected with the BRD and the latter becoming mildly infected. The responses of both these species were compared and interpreted with respect to their possible strategies of defense against the infectious agent. Starvation experiments were performed on $R$. philippinarum. 


\section{MATERIALS AND METHODS}

Challenge with pathogenic Vibrio P1. Wild specimens of Ruditapes decussatus (length (l) $=35.2 \mathrm{~mm}, \mathrm{SE}$ $=0.94, \mathrm{~N}=380$ ) were collected from the Rade de Brest (France) and reared specimens of Ruditapes philippinarum $(\mathrm{L}=36.6 \mathrm{~mm}, \mathrm{SE}=0.48, \mathrm{~N}=480)$ from the basin of Arcachon (France). Homogeneous samples were used since a preliminary study (to be reported separately) showed that, under normal conditions, hemocyte density in these molluscs varied with individual and population parameters (body weight, geographic origin). The bacterium used was Vibrio P1, the pathogenic agent of BRD (Paillard et al. 1989). The method
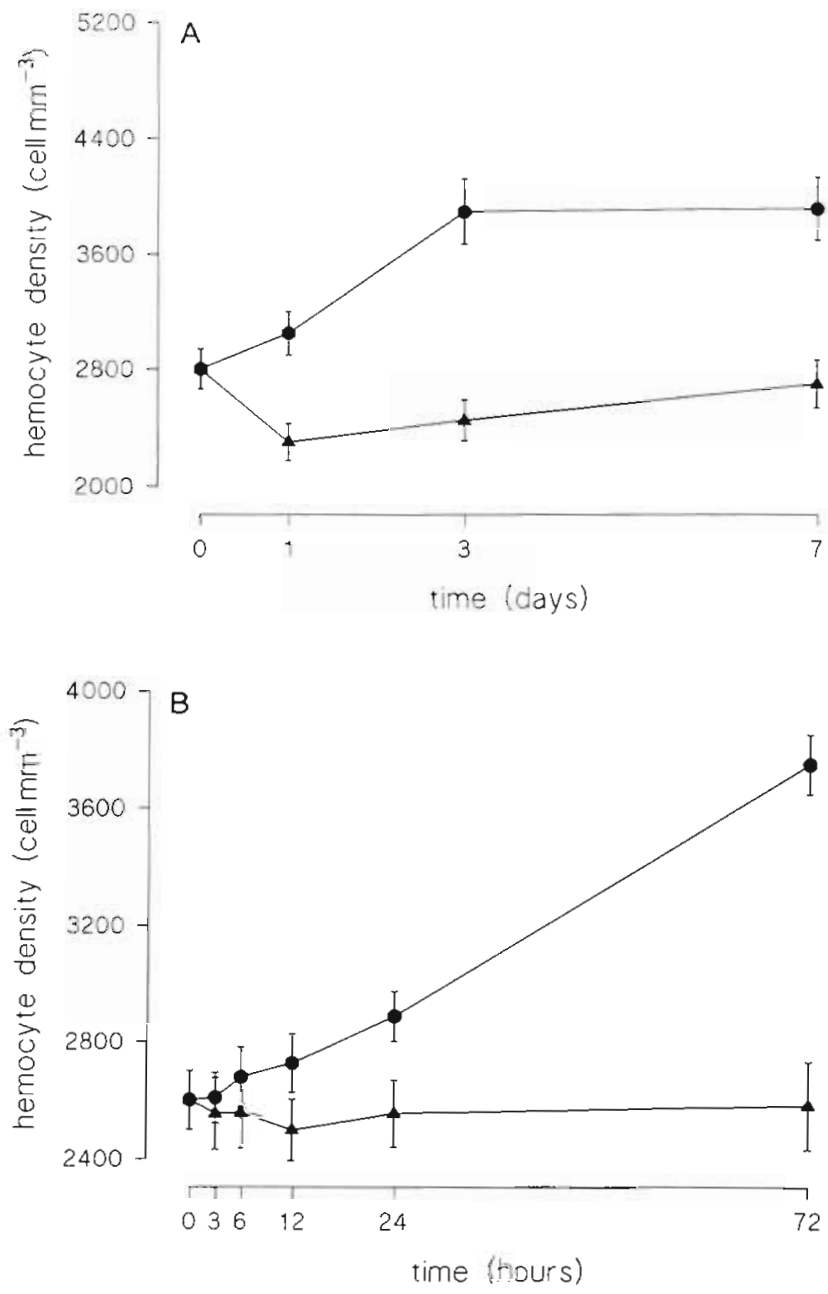

Fig. 1 Ruditapes philippinarum. Hemocyte density ( $\pm \mathrm{SE}$ ) after challenge with the bacterium Vibrio P1 (@) and control (4) expressed as the mean number of hemocytes per $\mathrm{mm}^{3}$ of hemolymph ( $\mathrm{n}=20)$. (A) Long-term experiment. (B) Short-term experiment of preparing the inoculum adopted here was that of Paillard \& Maes (1990). For the challenge experiments, a suspension of $10^{8}$ bacteria $\mathrm{ml}^{-1}$ in sterile seawater was prepared from a $72 \mathrm{~h}$ pure culture grown on marine agar. A volume of $0.5 \mathrm{ml}\left(5 \times 10^{7}\right.$ bacteria) from this suspension was inoculated into the pallial cavity of each experimental clam. After inoculation, clams were left out of water for $3 \mathrm{~h}$, and then placed in aerated seawater $\left(15^{\circ} \mathrm{C}\right)$. The clams were fed daily with cultured algae (Isochrysis galbana and Dunaliella euchlora) and every $3 \mathrm{~d}$ seawater was changed. Control clams were injected with $0.5 \mathrm{ml}$ seawater and maintained in similar conditions. Two experiments were performed, one long-term ( 0 to $7 \mathrm{~d}$ ) and the other short-term (0 to $72 \mathrm{~h}$ ). Hemocyte counts were made on 20 individuals sampled as described below. The same procedure was applied to both clam species.

Starvation experiments. Specimens of Ruditapes philippinarum were kept unfed in an aquarium for $1 \mathrm{wk}$. Hemocyte counts were performed on 20 individuals. Control clams were fed daily with algae.

Hemolymph sampling. Hemolymph was collected from the posterior adductor muscle sinus of each clam with a hypodermic syringe introduced through the hinge. A maximal volume of 0.10 to $0.15 \mathrm{ml}$ was withdrawn to sample only circulating hemolymph. In order to avoid hemocyte aggregation, fixative was added (vol: vol) to the sample. The fixative was $3 \%$ glutaraldehyde in $0.1 \mathrm{M}$ cacodylate buffer $\mathrm{pH}=7.4$ to which saccharose had been added (final osmolarity $=1100$ mOsmol kg ${ }^{-1}$ ). Hemocytes were counted in a Malassez hemocytometer and density expressed as the number of hemocytes per $\mathrm{mm}^{3}$ of hemolymph. The Student's $t$-test was employed to compare mean hemocyte density values.

\section{RESULTS}

\section{Challenge with pathogenic Vibrio P1}

When Ruditapes philippinarum was challenged with the bacterium, the number of circulating hemocytes increased significantly $(p<0.01)$ between 0 and $3 \mathrm{~d}$ (Fig. $1 A, B)$. In the long-term experiment, the hemocyte density remained constant after the third day at high values (4000 vs 2800 cells $\mathrm{mm}^{-3}$ at Day 0 ). From $1 \mathrm{~d}$ to $1 \mathrm{wk}$, all the values obtained after challenge with the bacterium were significantly greater $(p<0.01)$ than those observed for clams who received a seawater inoculum. At $1 d$, these control clams showed a slight decrease in hemocyte density which was not observed later. This initial decrease in circulating hemocytes at 

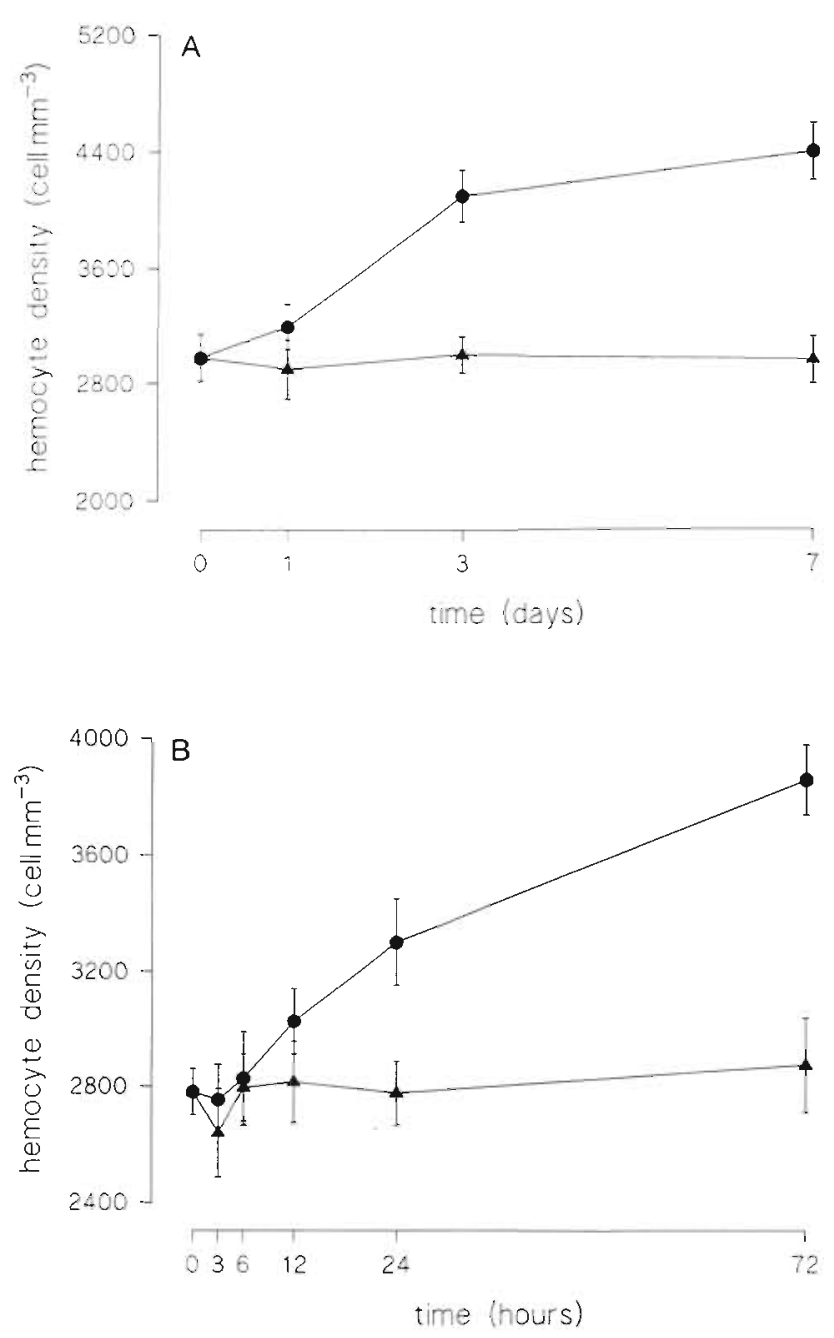

Fig. 2. Ruditapes decussatus. Hemocyte density ( \pm SE) after

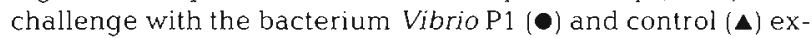
pressed as the mean number of hemocytes per $\mathrm{mm}^{3}$ of hemolymph $(n=20)$. (A) Long-term experiment. (B) Short-term experiment

the onset of the experiment was not observed during the short-term experiment (Fig. 1B). Thus, the maximal response of the clams was reached each time around $72 \mathrm{~h}$. The short-term experiment showed that a slight and regular increase in hemocyte density occurred after challenge from 0 to $3 \mathrm{~d}$ (Fig. 1B).

The results obtained for Ruditapes decussatus were comparable to those described above for $R$, philippinarum with respect to the number of hemocytes and the pattern of hemocyte density (Fig. 2A, B). Again, the hemocyte density in challenged clams increased significantly after $24 \mathrm{~h}(\mathrm{p}<0.05)$ in the short-term experiment and after $72 \mathrm{~h}(\mathrm{p}<0.01)$ in both experiments relative to the control animals. This early response at $24 \mathrm{~h}$, however, was not observed in the long-term experiment (Fig. 2A).

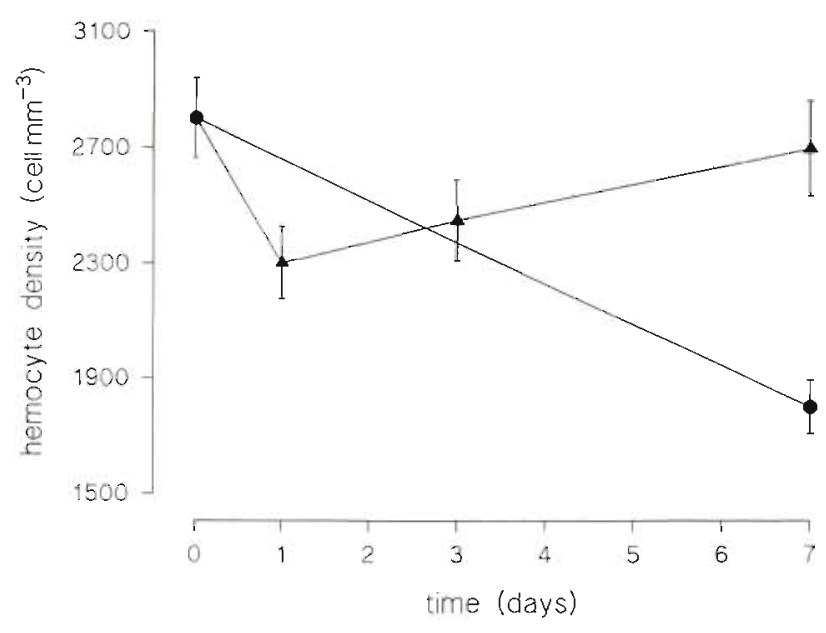

Fig. 3. Ruditapes philippinarum. Hemocyte density ( $\pm \mathrm{SE}$ ) in clams starved for 1 wk $(\bullet)$. Controls (A) were daily fed with algae (Isochrysis galbana and Dunaliella euchlora) ( $\mathrm{n}=20)$

\section{Starvation effects in Ruditapes philippinarum}

The hemocyte density decreased significantly ( $\mathrm{p}<$ $0.01)$ to approximately $65 \%$ compared to Day 0 values after 1 wk of fasting (Fig. 3). After a slight decrease in the sample at $24 \mathrm{~h}$, the hemocyte density of control clams was not different from that measured at Day 0.

\section{DISCUSSION}

These experiments show that the hemocyte density of Ruditapes philippinarum and $R$. decussatus increases after pallial cavity exposure to a pathogenic bacterium, Vibrio P1. Even if Vibrio P1 is a more virulent pathogen for $R$. philippinarum than $R$. decussatus (Maes \& Paillard 1992), this challenge caused significant changes in the hemolymph from both species Furthermore, the post-challenge evolution of hemocyte density was found to be comparable in both species. High hemocyte densities were maintained throughout the first week following inoculation However, it is emphasized that these species do not have the same susceptibility to the disease and probably not the same resistance capacity. Consequently, either the infectious process evolves in a different way in these species after this $1 \mathrm{wk}$ period, or the hemocyte density does not closely reflect the resistance state of the host. Paillard \& Maes (1990) have observed in $R$. philippinarum that the symptoms of BRD appear 2 wk after challenge with the bacterium, this delay being necessary for the development of the bacterial infection in the mollusc. The defense response of the clams during the period following the challenge is cer- 
tainly a major factor contributing to the success or failure of the infectious process.

Suresh \& Mohandas (1990) have observed an increase in the number of circulating hemocytes 6 to $12 \mathrm{~h}$ after infection of the bivalve Villorita cyprinoides by Vibrio alginolyticus and after $48 \mathrm{~h}$ in another species, Sunetta scripta. In our experiments, the hemocytic response was appreciable after $24 \mathrm{~h}$ and obvious at $72 \mathrm{~h}$. The early response observed in $V$. cyprinoides could be explained by the fact that the bacteria were injected through the epithelial layer. One of the 2 species investigated by Suresh \& Mohandas (1990) showed a very fast response. In our experiments, the increase of hemocyte density was never significant before $24 \mathrm{~h}$. Comparing all these results, it appears that the hemocytic response after challenge with bacteria may depend on the bivalve species as well as the pathogen. Gastropod molluscs have also been observed to have a hemocytic response after a parasite infestation began, with a delay varying from several hours (Stumpf \& Gilbertson 1978) to several days (Lie et al. 1980, Mounkassa \& Jourdane 1990). The response of hosts to pathogens appears highly variable and obviously depends of the nature of the pathogenic stimulus.

A different response was induced by starvation in Ruditapes philippinarum where the hemocyte density significantly decreased by 1 wk. A comparable phenomenon has been observed in crustaceans after starvation by Stewart et al. (1967) and Bauchau \& Plaquet (1973), but the underlying physiological mechanisms were not identified. Nevertheless, it is assumed that these variations in hemocyte density may correspond either to a modified number of hemocytes in the mollusc's circulatory system or to a modified hemopoiesis that changes the absolute number of hemocytes. The first hypothesis stems from the anatomy of these organisms which have an open circulatory system and hemolymph cells occur either in the circulating compartment or in the tissue compartment. The second hypothesis involves a production of young cells by hemopoeisis, but the regulation of this process and its sensitivity to internal and external stimuli are poorly understood in bivalve molluscs (Auffret 1988).

Reversible mobilization of hemocytes between the tissues and the circulatory system considered as a distribution compartment, will cause changes in the number of circulating hemocytes. Such a migration may be induced in molluscs by various physiological or pathological stimulations (Adema et al, 1991). Which sites are more probably involved in this phenomena? In the gastropod Patella vulgata, challenge with bacteria resulted in an increase in the number of circulating hemocytes and drastically reduced the number of hemocytes observed in the tissues (Cooper-Willis 1979), In the same way, Mounkassa \& Jourdane (1990) found in the gastropod Biomphalaria glabrata challenged with bacteria, that the decrease in the number of circulating hemocytes was a result of the mobilization of hemocytes in the tissues in response to an increasing demand for nutrients by the host and/or to repair wounds caused by the pathogen. In case of an infectious process, the capacity for hemocyte redistribution in the organism might be interpreted as an increase in the efficiency of the internal defense system by providing defensively active cells at sites of pathogenic aggression (Smith \& Ratcliffe 1980, Loker et al. 1987). In Ruditapes philippinarum, we observed a return to initial hemocyte densities once feeding had resumed (unpubl. data). Since hemocytes have been implicated in the functioning of the digestive system and the transport of metabolic material, an accumulation of hemocytes in storage tissues would allow the utilization of these metabolic reserves by starved molluscs (Bäghdiguian \& Riva 1984, Bielefeld 1991).

The migration of hemocytes from one anatomical compartment to another, or from one tissue to another, is induced and controlled by internal signals and mediators. In the case of starvation, some modification in the make-up of the hemolymph, such as the concentration of metabolites, could be a signal for hemocyte mobilization. Indeed, when in unfed conditions, the total plasma proteins of the crab Carcinus maenas declined along with a simultaneous decrease in hemocyte density (Stewart et al. 1967). In the case of a bacterial infection, the migration of hemocytes into the circulatory system might be interpreted as a response of the organism, contributing to the internal defense system. Then, hemocyte mobilization could be provoked by some bacteria-related factor. Nottage \& Birkbeck (1990) showed that cultured bacteria secreted substances with cytotoxic effects against bivalve hemocytes. Inversely, phagocytic hemocytes of bivalve molluscs possess chemotaxis towards bacteria (Cheng et al. 1981, Howland \& Cheng 1982). More generally, when considering the response at the organism's level, it is assumed that cells in the molluscs may produce endogenous mediators of its immunodefense system in response to pathogenic stimulations. Identification of such signals involved in the hemocytic response will require further experiments, considering various endogenous and exogenous substances.

Acknowledgements. The authors thank Dr B. Simon for his help in computer-drawing of the figures, and Dr W. S. Fisher for reviewing this manuscript.

\section{LITERATURE CITED}

Adema, C M., Van der Knaap, W. P. W., Sminia, I (1991) Molluscan hemocyte-mediated cytotoxicity: the role of reactive oxygen intermediates. Aquat. Sci. 4 (2-3): 201-223 
Auffret, M. (1988). Bivalve hemocyte morphology. Am. Fish. Soc. Spec. Publ. 18: 169-177

Bauchau, A., Plaquet, J. (1973). Variation du nombre des hémocytes chez les crustacés brachyoures. Crustaceana 24: $215-223$

Baghdiguian, S., Riva, A. (1984). Etude des adaptations physiologiques entrainées par un jeûne prolongé chez Ruditapes decussatus, bivalve endogé. Haliotis 14 $119-130$

Bielefeld, U. (1991). Histological observation of gonads and digestive gland in starving Dreissena polymorpha (Bivalvia). Malacologia 33 (1-2): 31-42

Cheng, T. C. (1981). Bivalves. In: Ratcliffe, N. A., Rowley, A. F. (eds.) Invertebrate blood cells, Vol. 1. Academic Press London, p. 231-300

Cheng, T. C., Nguyen Bui, M., Howland, K. H., Schoenberg, D. A., Sullivan, J. T. (1981). Effect of preinjection of Crassostrea virginica with bacteria on subsequent chemotactic response by its hemocytes. J. Invertebr. Pathol. 38 : $122-126$

Cooper-Willis, C. A. (1979). Changes in acid phosphatase levels in the haemocytes and haemolymph of Patella vulgata after challenge with bacteria. Comp. Biochem. Physiol. 63A: $627-631$

Fisher, W. S. (1986). Structure and function of oyster hemocytes. In: Brehelin, M. (ed.) Immunity in invertebrates. Springer-Verlag, Berlin, p. 25-35

Fisher, W. S. (ed.) (1988). Disease processes in marine bivalve molluscs. Am. Fish. Soc. Spec. Publ. 18: 1-315

Howland, K. H., Cheng, T. C. (1982). Identification of bacterial chemoattractants for oyster (Crassostrea virginica) hemocytes. J. Invertebr. Pathol. 39: 123-132

Lie, K. J., Jeong, K. H., Heyneman, D. (1980). Inducement of miracidia-immobilizing substance in the hemolymph of Biomphalaria glabrata. Int. J. Parasitol. 10:183-188

Loker, E. S., Cimino, D. F., Stryker, G. A., Hertel, L. A. (1987). The effect of size of $M$ line Biomphalaria glabrata on the

Responsible Subject Editor: A. K. Sparks, Seattle, Washington, USA course of development of Echinostoma paraensei. J. Parasitol. 73 (6): 1090-1098

Maes, P., Paillard, C. (1992). Effet de Vibrio P1, pathogène de Ruditapes philippinarum sur d'autres espèces de bivalves Haliotis 14: 141-148

Mounkassa, J. B., Jourdane, J. (1990). Dynamics of the leukocytic response of Biomphalaria glabrata during the larval development of Schistosoma mansoni and Echinostoma liei. J. Invertebr. Pathol. 55: 306-311

Nottage, A. S., Birkbeck, T. H. (1990). Interactions between different strains of Vibrio alginolyticus and hemolymph fractions from adult Mytilus edulis. J. Invertebr. Pathol. 56 : 15-19

Paillard, C., Maes, P. (1990). Etiologie de la maladie de l'anneau brun chez Tapes philippinarum: pathogénicité d'un Vibrio sp. C. r. Acad. Sci. Paris 310 (III): 15-20

Paillard, C., Percelay, L., Le Pennec, M., Le Picard, D. (1989). Origine pathogène de 'I'anneau brun' chez Tapes philippinarum (Mollusque, bivalve). C. r. Acad. Sci., Paris 309 (III): $235-241$

Smith, V. J., Ratcliffe, N. A. (1980). Host defence reactions of the shore crab, Carcinus maenas (L.): clearance and distribution of injected test particles. J. mar. Biol. Ass. U. K. 89: 89-102

Stewart, J. E., Dingle, J. R., Odense, P. H. (1967). An electronic method for counting lobster (Homarus americanus Milne Edwards) hemocytes and the influence of diet on hemocyte numbers and hemolymph proteins. Can. J. Zool. 45: $291-304$

Stumpf, J. F., Gilbertson, D. E. (1978). Hemocytes of Biomphalaria glabrata: factors affecting variability. J Invertebr. Pathol. 32: 177-181

Suresh, K., Mohandas, A. (1990). Number and types of hemocytes in Sunetta scripta and Villorita cyprinoides var. cochinensis (bivalvia), and leukocytosis subsequent to bacterial challenge. J. Invertebr. Pathol. 55 $312-318$

Manuscript first received: April 1, 1992

Revised version accepted: January 7, 1993 